\title{
Media-assisted machining processes using nano-fluids. Part 2: Examples of the influence of nano-fluids on the cutting process
}

\author{
Hybrydowe procesy skrawania wspomagane nanocieczami. \\ Część 2: Przykłady wpływu nanocieczy na proces skrawania
}

\section{WIT GRZESIK*}

The comprehensive knowledge of the applications of nano-fluids for hybrid machining processes assisted by liquid media, which, in general, are applied in MQL systems is presented. In the first part of the article properties of nano-additives, which are added to base cutting fluids (such as vegetable and mineral oils and emulsion), and their influence on the performance of machining processes were outlined. The tribological mechanisms including rolling and plowing of the nano-particles in the contact zones, as well as resulting thermal influences were characterized. In the second part of the article, some practical examples of the possible influences of different nano-fluids on the cutting temperature, tool wear and tool life, surface roughness and surface quality are provided and discussed. It was concluded that nano-fluids with graphene and carbon nanotubes additives are very effective in improving process behaviour. KEYWORDS: nano-particles, nano-fluids, MQL, machining, grinding

Przedstawiono zwięzłe informacje na temat zastosowania nanocieczy do wspomagania hybrydowych procesów skrawania mediami ciekłymi, które zasadniczo znalazły zastosowanie w minimalnym smarowaniu/chłodzeniu MQL. W pierwszej części artykułu omówiono właściwości dodawanych do cieczy bazowych (olejów roślinnych i mineralnych oraz emulsji) nanocząstek i ich wpływ na przebieg procesu skrawania. Scharakteryzowano mechanizmy tribologiczne w strefie kontaktu i pochodne oddziaływania termiczne. W drugiej części artykułu zostaną opisane praktyczne przykłady wpływu nanocieczy na temperaturę skrawania, przebieg zużycia i trwałość ostrza oraz chropowatość i jakość powierzchni. Wykazano dużą efektywność zastosowania nanocieczy z dodatkami grafenu i nanorurek. SŁOWA KLUCZOWE: nanocząstki, nanociecze, ciecze obróbkowe, MQL, skrawanie, szlifowanie

\section{Wprowadzenie}

Artykuł jest kontynuacją poprzednich publikacji autora w miesięczniku Mechanik [1,2], poświęconych problematyce hybrydowych procesów obróbkowych z zastosowaniem różnych form i technik hybrydyzacji i ich znaczeniu w nowoczesnym przemyśle wytwórczym. Omówiono w nich m.in. metody wspomagania procesu skrawania przez wprowadzenie dodatkowych mediów ciekłych, gazowych i stałych do strefy skrawania.
W tym artykule zwraca się uwagę na poprawę efektywności metod oszczędnego smarowania/chłodzenia (MQL/C) przez zastosowanie tzw. nanocieczy (nano-fluids). Badania nad tymi zagadnieniami od ponad dekady są intensywnie prowadzone na świecie, a ich rezultatem są liczne propozycje dodawania do bazowych cieczy obróbkowych (tj. emulsji, olejów roślinnych i mineralnych) nanocząsteczek metalicznych, niemetalicznych i ceramicznych. W pierwszej części artykułu omówiono właściwości nanocząstek i ich wpływ na proces skrawania [19]. W tej części natomiast zostaną omówione przykłady tego wpływu na temperaturę skrawania, trwałość ostrza i chropowatość powierzchni.

\section{Temperatura skrawania}

$\mathrm{Na}$ rys. 1 przedstawiono rozkład temperatury wzdłuż styku wióra z powierzchnią natarcia ostrza podczas skrawania dwufazowego $(\alpha+\beta)$ stopu tytanu Ti6Al4V. Widać wyraźne obniżenie temperatury i zmianę trendu w rozkładzie temperatury, gdy do cieczy bazowej dodano wieloboczne nanorurki

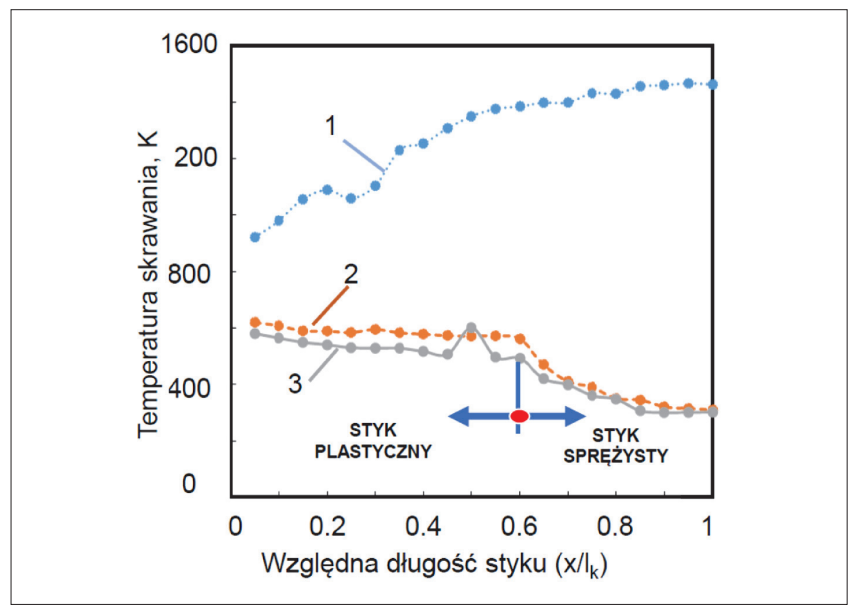

Fig. 1. Temperature distribution along the tool-chip contact without addition of MWCNTs particles and with the addition of MWCNTs particles in the machining of Ti6Al4V alloy [9]. Markings: 1 - pure MQL, 2 - with the addition of $2 \%$ by weight, 3 - with the addition of $4 \%$ by weight

Rys. 1. Rozkład temperatury wzdłuż kontaktu wiór-ostrze bez dodatku cząstek MWCNTs i z dodatkiem cząstek MWCNTs w skrawaniu stopu Ti6Al4V [9]. Symbole: 1 - czyste MQL, 2 - MQL z dodatkiem cząstek o koncentracji $2 \% \mathrm{wt}, 3$ - z dodatkiem cząstek o koncentracji $4 \% \mathrm{wt}$

\footnotetext{
* Prof. dr hab. inż. Wit Grzesik, w.grzesik@po.edu.pl, https://orcid.org/0000-0003-3898-5119 - Katedra Technologii Maszyn
} i Automatyzacji Produkcji Politechniki Opolskiej, Opole, Polska 


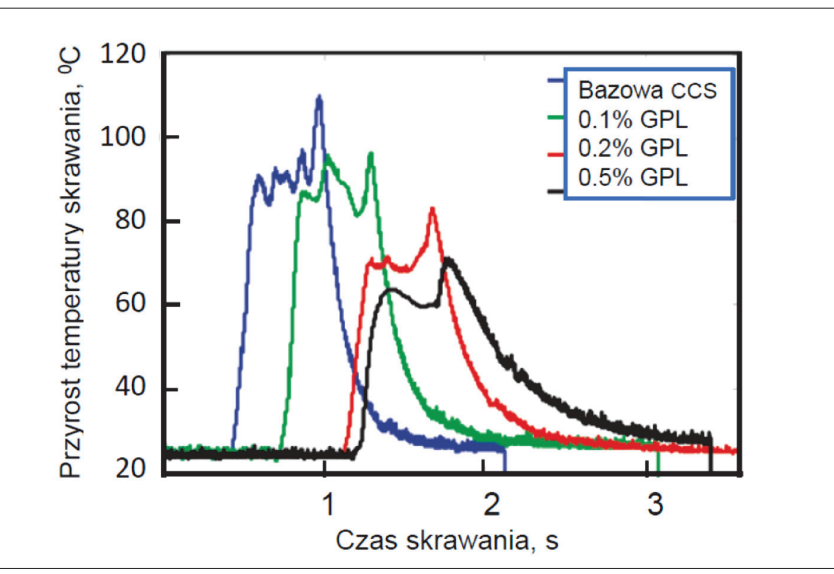

Fig. 2. The change in temperature distribution during micro-turning caused by the addition of graphene nano-particles (GPL) with different concentrations [14]

Rys. 2. Zmiana rozkładu temperatury w czasie mikrotoczenia wywołana dodatkiem nanocząstek grafenu (GPL) o różnej koncentracji [14]

(multi-walled carbon nano-tubes - MWCNTs) o koncentracji $2 \%$ wt i $4 \%$ wt. Można również zauważyć, że rozkład temperatury dla MQL z zastosowaniem nanocieczy (nano-fluid-assisted MQL - NFAMQL) jest podobny do klasycznego rozkładu naprężeń stycznych w tej strefie [8], tj. w strefie styku plastycznego temperatura jest praktycznie stała, o wartości ok. $500 \mathrm{~K}$, a na końcu styku sprężystego spada do ok. $350 \mathrm{~K}$.

$\mathrm{Na}$ rys. 2 zestawiono zapisy zmian temperatury skrawania dla bazowej cieczy chłodząco-smarującej (CCS) i trzech wagowych dodatków drobinek grafenu (graphene platelets - GPL) (0,1\%; 0,2\% i 0,5\% wt). Można zauważyć, że dodatek GPL w nanocieczy znacznie wpływa na maksymalną wartość temperatury i powoduje zahamowanie jej przyrostu w czasie obróbki (odpowiednio o: 6, 30 i 40\%). Efekt ten jest najbardziej widoczny przy najwyższej koncentracji zawiesiny koloidalnej - 0,5\% wt. Co więcej, fluktuacje temperatury są dla nanocieczy mniejsze niż dla bazowej cieczy półsyntetycznej. Zmiany te mają ścisły związek z sygnalizowanym wcześniej wpływem na redukcję tarcia i obniżenie temperatury skrawania. Ustalono również, że wpływ dodania $0,5 \%$ jednobocznych nanorurek węglowych (single-walled carbon nano-tubes - SWCNTs) i 0,5\% MWCNTs do cieczy bazowej jest podobny do omówionego wpływu dodania grafenu.

\section{Zużycie i trwałość ostrza narzędzia}

Wielokrotnie podkreślano, że nanociecze powodują redukcję tarcia $\mathrm{w}$ strefie skrawania, co prowadzi do spowolnienia zużycia ostrza. Na rys. 3 - który przedstawia ślady zużycia wykryte podczas skrawania stopu Ti6Al4V ze smarowaniem MQL wspomaganym nanocieczą zawierającą nanocząsteczki tlenku aluminium $\left(\mathrm{Al}_{2} \mathrm{O}_{3}\right)$ i wieloboczne nanorurki (MWCNTs) - zweryfikowano tę hipotezę. Ocena zużycia ostrza dotyczy ścierania mechanicznego powierzchni przyłożenia (rys. 3a) i tworzenia krateru na powierzchni natarcia (rys. $3 b$ ).

Na rys. 3 widać wyraźne różnice $\mathrm{w}$ mechanizmach i intensywności zużycia ostrza, gdy zastosowano dodat-
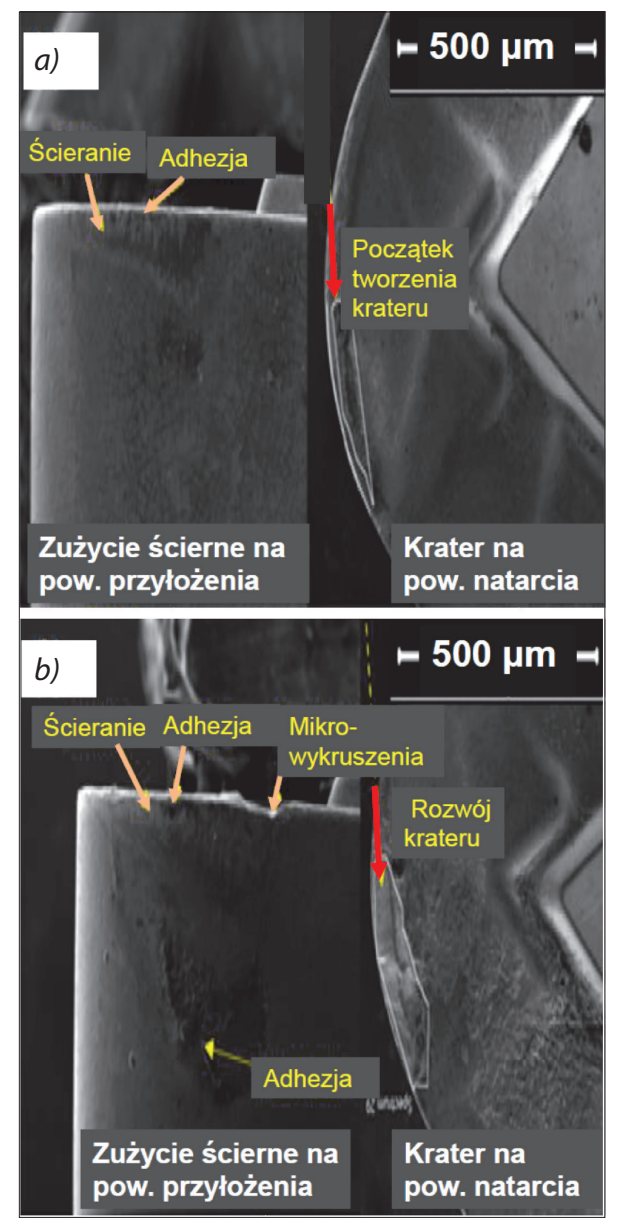

Fig. 3. Comparison of the tool wear mechanisms during machining: a) with MQL assisted by nano-fluid and $b$ ) with classic MQL. Cutting parameters: cutting speed $-170 \mathrm{~m} / \mathrm{min}$, feed $-0.15 \mathrm{~mm} / \mathrm{rev}$. Workpiece - titanium alloy Ti6Al4V [10]

Rys. 3. Porównanie mechanizmów zużycia ostrza podczas obróbki: a) z MQL wspomaganym nanocieczą i b) z klasycznym MQL. Parametry skrawania: prędkość skrawania - $170 \mathrm{~m} / \mathrm{min}$, posuw $-0,15 \mathrm{~mm} /$ obr. Materiał obrabiany - stop tytanu Ti6AI4V [10]

kowe wspomaganie oszczędnego smarowania MQL nanocieczą (NFAMQL). Na rys. $3 b$ zarówno zużycie ścierne na powierzchni przyłożenia, jak i tworzenie się krateru przebiegają zauważalnie intensywniej w porównaniu z przypadkiem NFAMQL. Świadczy to jednoznacznie o redukcji tarcia i intensywniejszym odprowadzaniu ciepła przez nanociecz o większych zdolnościach przenikania ciepła. Należy jednak uwzględnić dodatkowe zużycie spowodowane przez wprowadzone do klasycznego MQL nanododatki (rys. 4). Z rys. 4 wynika, że przyrost zużycia spowodowany efektem ściernego oddziaływania nanododatków jest znacznie większy dla nanocząstek, np. twardych cząstek $\mathrm{Al}_{2} \mathrm{O}_{3}$, niż dla nanorurek węglowych (carbon nanotubes - CNTs).

$\mathrm{Z}$ rys. 5 wynika, że nanociecze $\mathrm{z}$ dodatkiem grafitu w dużo większym stopniu redukują zużycie ostrza niż mieszaniny z dodatkami $\mathrm{Al}_{2} \mathrm{O}_{3}$ i $\mathrm{MoS}_{2}$. Wynika to $\mathrm{z}$ faktu, że mocne wiązania kowalentne w strukturze siatki atomowej grafitu sprzyjają rozwojowi tocznego mechanizmu ruchu nanocząstek, co prowadzi do redukcji tarcia, zwłaszcza w konfrontacji ze strukturą atomową aluminium [7]. Należy jednak zauważyć, że dostrzegalny efekt wpływu dodatku grafitu do nanocieczy ustalono dla prędkości skrawania powyżej $250 \mathrm{~m} / \mathrm{min}$ (przebieg \#3 na rys. 5). 


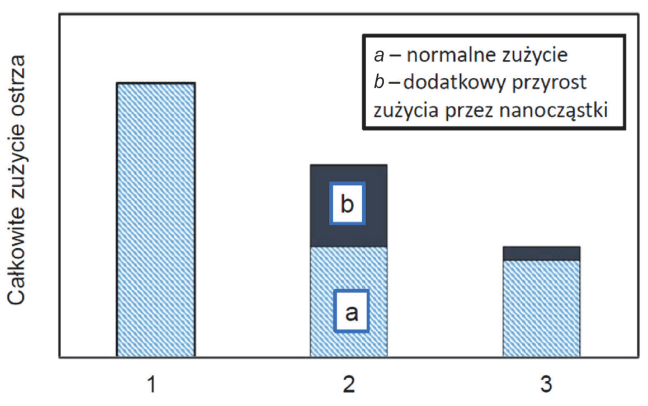

Fig. 4. Comparison of the blade wear structure with MQL and NFAMQL according to [9]. Markings: 1 - without nano-additives, 2 - with nano-particles, 3 - with nano-tubes

Rys. 4. Porównanie struktury zużycia ostrza z MQL i NFAMQL według [9]. Oznaczenia: 1 - bez nanododatków, 2 - z nanocząsteczkami, 3 - z nanorurkami

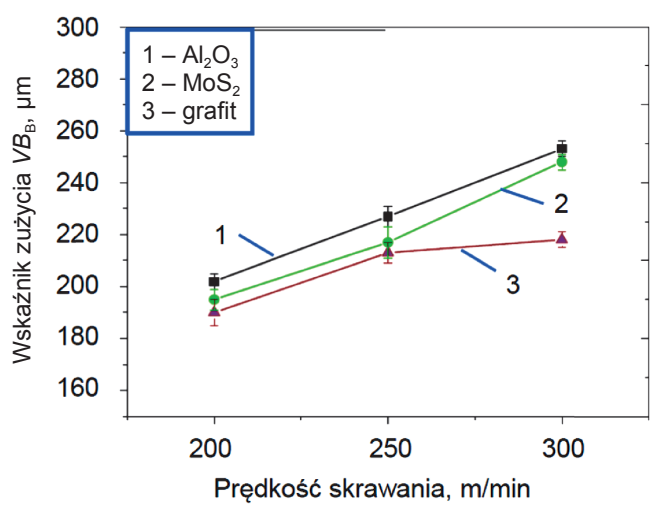

Fig. 5. The influence of cutting speed on the wear of the blade in the cutting of Inconel 800 alloy with the use of different nanofluids $\left(\mathrm{Al}_{2} \mathrm{O}_{3}, \mathrm{MoS}_{2}\right.$ and graphite additives) [7]. Cutting parameters: $f=0.15 \mathrm{~mm} / \mathrm{rev}, a_{\mathrm{p}}=0.50 \mathrm{~mm}$

Rys. 5. Wpływ prędkości skrawania na zużycie ostrza w skrawaniu stopu Inconel 800 z zastosowaniem różnych nanocieczy (dodatki: $\mathrm{Al}_{2} \mathrm{O}_{3}, \mathrm{MoS}_{2}$ i grafitu) [7]. Parametry skrawania: $f=0,15 \mathrm{~mm} / \mathrm{obr}$, $a_{\mathrm{p}}=0,50 \mathrm{~mm}$

W tablicy zestawiono niektóre dane literaturowe dotyczące wydłużenia okresu trwałości ostrza w wyniku zastosowania techniki NFAMQL, gdy testowano zasadność dodania do cieczy bazowej nanocząstek,

TABLE. Increase of the tool life $(T)$ resulting from the use of various nano-fluids [15]

TABLICA. Wzrost okresu trwałości ostrza $(T)$ dzięki zastosowaniu różnych nanocieczy [15]

\begin{tabular}{|l|c|}
\hline \multicolumn{1}{|c|}{ Rodzaj nanocieczy } & $\begin{array}{c}\text { Wynikowy okres } \\
\text { trwałości }\end{array}$ \\
\hline $\begin{array}{l}\text { Olej mineralny z dodatkiem } \\
\text { nanocząstek CuO }\end{array}$ & Wzrost do $600 \%$ \\
\hline $\begin{array}{l}\text { Olej sojowy z dodatkiem nanocząstek } \\
\mathrm{Al}_{2} \mathrm{O}_{3}\end{array}$ & Wzrost o $180 \%$ \\
\hline $\begin{array}{l}\text { Olej roślinny z dodatkiem nanocząstek } \\
\mathrm{Al}_{2} \mathrm{O}_{3}\end{array}$ & Wzrost o $20 \%$ \\
\hline $\begin{array}{l}\text { Olej roślinny z dodatkiem nanocząstek } \\
\mathrm{Al}_{2} \mathrm{O}_{3} / \text { MWCNT }\end{array}$ & Widoczny efekt \\
\hline $\begin{array}{l}\text { Dejonizowana woda z dodatkiem } \\
\text { nanocząstek TiO }\end{array}$ & Wzrost do 70\% \\
\hline $\begin{array}{l}\text { Glikol etylenowy z dodatkiem } \\
\text { nanocząstek TiO }\end{array}$ & Wydłużony okres T \\
\hline $\begin{array}{l}\text { Olej roślinny z dodatkiem nanocząstek } \\
\text { grafenu }\end{array}$ & Wzrost o $180 \%$ \\
\hline
\end{tabular}

takich jak: $\mathrm{Al}_{2} \mathrm{O}_{3}, \mathrm{TiO}_{2}, \mathrm{CuO}, \mathrm{MWCNT}$ i nGr (grafen). Wydłużenie trwałości zawiera się w przedziale $20 \div 600 \%$ w zależności od gatunku materiału obrabianego i warunków obróbki.

\section{Chropowatość powierzchni}

Ważna grupa możliwych oddziaływań nanocieczy dotyczy chropowatości powierzchni generowanej w procesie obróbkowym. Zasadniczo jakość powierzchni poprawia się $\mathrm{w}$ porównaniu $\mathrm{z}$ obróbką na sucho i MQL z zasilaniem cieczą bazową. Ma to związek z tworzeniem przez nanododatki cienkiego filmu chroniącego przed ścieraniem powierzchnię styku narzędzie-powierzchnia obrabiana.

Na rys. 6 można dostrzec, że w przypadku obróbki na sucho i chłodzenia gazem parametr chropowatości powierzchni $R a$ jest równy ok. 0,65 $\mu \mathrm{m}$, natomiast wyraźnie zmniejsza się odpowiednio do $0,4 \mu \mathrm{m}$ i $0,3 \mu \mathrm{m}$ po zastosowaniu konwencjonalnych metod MQL i NFAMQL. Oznacza to, że parametr $R a$ zmniejsza się o ponad $50 \%$, gdy zamiast obróbki na sucho do cieczy

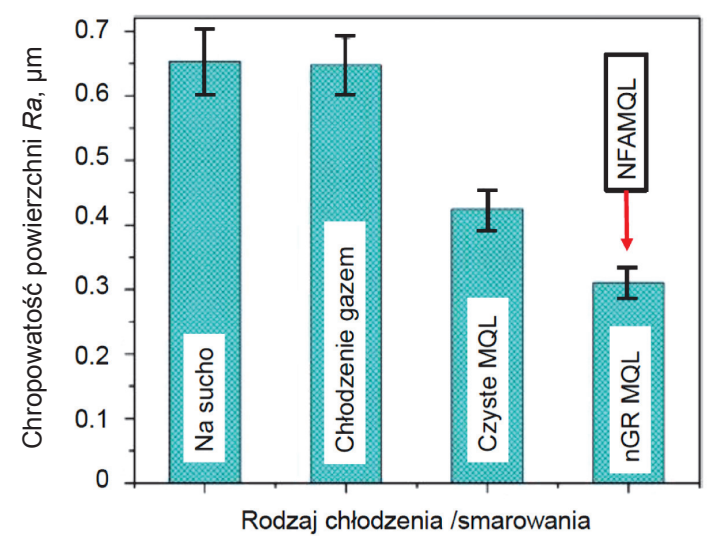

Fig. 6. Comparison of the milled surface roughness parameter for various cooling/lubrication methods [12]

Rys. 6. Porównanie parametru chropowatości powierzchni frezowanej dla różnych sposobów chłodzenia/smarowania [12]

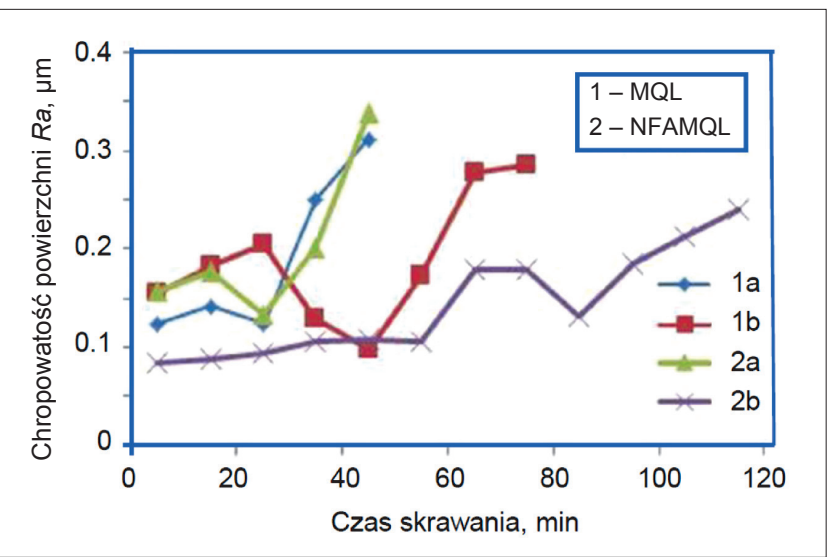

Fig. 7. Roughness change during milling with the use of pure MQL and MQL with nano-fluids [16]. Markings: $1 a-$ soybean oil, $1 b$ - emulsion, $2 a$ - soybean oil with $0.5 \% \mathrm{Al}_{2} \mathrm{O}_{3}$ nano-particles, $2 b$ - emulsion with $0.5 \% \mathrm{Al}_{2} \mathrm{O}_{3}$ nano-particles

Rys. 7. Zmiana chropowatości w czasie frezowania z zastosowaniem czystego MQL i z użyciem nanocieczy [16]. Oznaczenia: 1a - olej sojowy, $1 b$ - emulsja, $2 a$ - olej sojowy $z$ dodatkiem $0,5 \%$ nanocząstek $\mathrm{Al}_{2} \mathrm{O}_{3}, 2 b$ - emulsja $z$ dodatkiem $0,5 \%$ nanocząstek $\mathrm{Al}_{2} \mathrm{O}_{3}$ 
a)

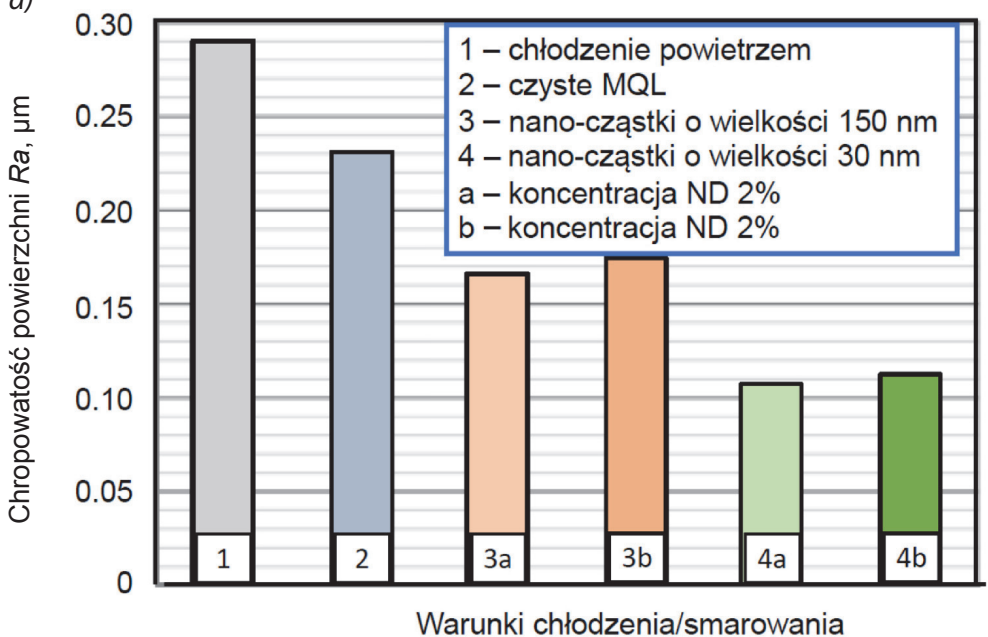

b)

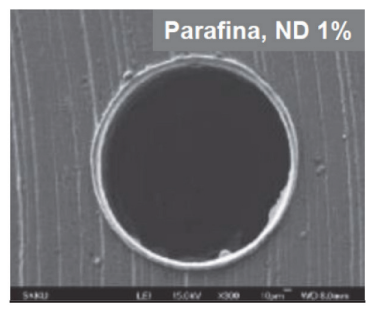

c)

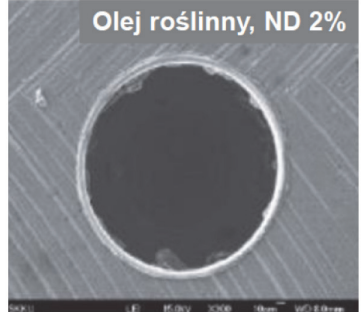

Fig. 8. Surface roughness after micro-grinding $(a)$ and the surface of micro-holes $(b, c)$ for various cooling/lubrication conditions [17, 18]. Machined materials: SK41C tool steel $(a)$; aluminum, grade $6061(b, c)$

Rys. 8. Chropowatość powierzchni po mikroszlifowaniu $(a)$ i powierzchnia mikrootworów $(b, c)$ dla różnych warunków chłodzenia/smarowania $[17,18]$. Materiały obrabiane: stal narzędziowa SK41C (a); aluminium z gatunku $6061(b, c)$

dodano grafen (nGr). Przyczyną tego jest tworzenie się filmu olejowego z zawiesiną nanocząstek grafenu.

Na rys. 7 można zaobserwować, że parametr chropowatości zmienia się $\mathrm{w}$ zakresie $R a=0,08 \div 0,2 \mu \mathrm{m}$ (równoważnie: $R z=0,5 \div 1,5 \mu \mathrm{m}$ ) podczas frezowania stali stopowej 60Si2Mn o twardości 50 HRC, gdy z jednej strony stosuje się smarowanie olejem sojowym i emulsją (przebiegi \#1a i 2a), a z drugiej - do $5 \%$ emulsji dodaje się nanocząstki $\mathrm{Al}_{2} \mathrm{O}_{3}$ o koncentracji 0,5\%. W tym przypadku chropowatość powierzchni jest utrzymywana przez 60 min testu frezowania. W następnych 60 min wzrasta do ok. 0,2 $\mu \mathrm{m}$ po osiągnięciu przez wskaźnik zużycia powierzchni przyłożenia wartości $V B_{\mathrm{B}}=0,4 \mathrm{~mm}$ [16].

$\mathrm{Na}$ rys. $8 a$ przedstawiono wartości parametru chropowatości powierzchni $(R a)$ powierzchni po mikroszlifowaniu z zastosowaniem chłodzenia powietrzem, czystego MQL i NFAMQL. Można zauważyć, że chropowatość powierzchni zmniejsza się do wartości $0,10 \div 0,12 \mu \mathrm{m}$ po dodaniu do bazowej cieczy (oleju roślinnego) cząstek nanodiamentu (ND). Najmniejszą wartość $R a$ otrzymano, gdy dodano cząstki ND o wymiarze $30 \mathrm{~nm}$ i koncentracji $2 \%$. Podobny rezultat uzyskano po dodaniu do aerozolu MQL nanocząsteki $\mathrm{Al}_{2} \mathrm{O}_{3}$ o tej samej wielkości i koncentracji [17]. Wyjaśnienia tego faktu można upatrywać w większej intensywności absorpcji nanocząstek ND w strefie szlifowania i dominującej obecności mechanizmu obrotu nanododatków.

Na rys. $8 b, c$ pokazano obrazy SEM krawędzi mikrootworów wykonywanych bez użycia nanociezy i z użyciem nanocieczy (MQL + ND). Przypadki 8b i 8c odnoszą się odpowiednio do zastosowania nanocieczy z parafiny (rys. 8b) i oleju roślinnego (rys. 8c) oraz dodatku nanodiamentu o koncentracji objętościowej 1\% i 2\% wt. Na obrazach SEM można dostrzec, że wskutek ściernego działania ultratwardych nanocząstek diamentu zostają usunięte zadziory na krawędziach otworów i brak jest przywarć adhezyjnych mikrowiórów.

\section{Wnioski}

Skrawanie wspomagane nanocieczami w systemie MQL (NFAMQL) poprawia przebieg procesu w takich ważnych aspektach, jak: temperatura kontaktowa, tarcie, zużycie i trwałość ostrza.

Nanociecze poprawiają zwilżalność na powierzchniach kontaktowych ostrza i zwiększają przenikalność cieplną wskutek obecności zawiesiny o dużej przewodności cieplnej, co prowadzi do bardziej efektywnego odprowadzania ciepła w porównaniu z konwencjonalnymi CCS.

Można wyróżnić dwa podstawowe mechanizmy wpływu nanododatków do cieczy bazowych, tj. ich obrotu i przemieszczania się po powierzchni. Pierwszy mechanizm powoduje, że nanocząstki i nanorurki działają jako nanorolki i w ten sposób redukują tarcie w strefie kontaktu. W przypadku drugiego mechanizmu nanocząstki pozostają na powierzchni i tworzą cienką, złuszczoną warstwę zabezpieczającą przed przepływem ciepła do obrabianego przedmiotu.

Spośród wielu testowanych nanododatków najbardziej efektywne okazały się grafen (nGr) i wieloboczne nanorurki (MWCNTs). Mniejszy wpływ na przebieg procesu skrawania mają nanocząstki $\mathrm{Al}_{2} \mathrm{O}_{3}$. Duże znaczenie ma koncentracja nanododatków w cieczy bazowej.

Korzystne właściwości nanocieczy stosowanych w MQL sprawiają, że zrównoważoność procesu (proces sustainability) można wykazać nie tylko w odniesieniu do ochrony środowiska, ale także oszczędności energii oraz kosztów i czasu obróbki.

\section{LITERATURA}

[1] Grzesik W. „Hybrydowe procesy obróbki ubytkowej. Definicje, zasady tworzenia i znaczenie w przemyśle". Mechanik. 91, 5-6 (2018): 338-341, https://doi.org/10.17814/ mechanik.2018.5-6.50.

[2] Grzesik W. „Hybrydowe procesy skrawania wspomagane mediami technologicznymi" ("Media-assisted machining processes"). Mechanik. 91, 12 (2018): 1050-1056, DOI: https://doi.org/10.17814/mechanik.2018.12.186. 
[3] Kulkarni H.B., Nadakatti M.M., Patil M.S., Kulkarni R.M. "A review on nanofluids for machining". Current Nanoscience. 13, 6 (2017): https://doi.org/10.2174/15734137 13666170623094121.

[4] Sidik N., Samion S., Ghaderian J., Yazid M. "Recent progress on the application of nanofluids in minimum quantity lubrication machining. A review". Int. Journal of Heat and Mass Transfer. 108 (2017): 79-89, https://doi. org/10.1016/j.ijheatmasstransfer.2016.11.105.

[5] Shokoohi Y., Shekarian E. „Application of nanofluids in machining processes - a review". J. Nanoscience and Technology. 2 (2016): 59-63, https://www.researchgate.net/ publication/325514175_Application_of_Nanofluids_in_ Machining_Processes_-_A_Review.

[6] Khandekar S., Sankar M., Ramkumar J. "Nano-cutting fluid for enhancement of metal cutting performance". Materials and Manufacturing Processes. 27 (2012): 1-5, https://doi org/10.1080/10426914.2011.610078.

[7] Gupta M., Jamil M., Wang X., Song Q., Liu Z., Mia M., et. al. "Performance evaluation of vegetable oil-based nano-cutting fluids in environmentally friendly machining of Inconel-800 alloy". Materials. 12 (2019): 2702, https://doi org/10.3390/ma12172792.

[8] Grzesik W. „Podstawy skrawania materiałów konstrukcyjnych". Warszawa: PWN, 2018.

[9] Hegab H., Umer U., Esawi A., Kishawy H.A. “Tribological mechanisms of nano-cutting fluid minimum quantity lubrication: a comparative performance analysis model". Int J. Advanced Manufacturing Technology. 108 (2020): 3133-3139, https://doi.org/10.1007/s00170-020-05450-3.

[10] Hegab H., Darras B., Kishawy H.A. "Sustainability assessment of machining with nano-cutting fluids". Procedia Manufacturing. 26 (2018): 245-254, https://doi.org/10.1016/j.promfg.2018.07.033.

[11] Hegab H., Kishawy H.A., Umer U., Mohany A. "A model for machining with nano-additives based minimum quantity lubrication", Int. J. Advanced Manufacturing Technology. 102 (2019): 2013-2028, https://doi.org/10.1007/ s00170-019-03294-0.

[12] Li M., Yu T., Zhang R., Yang L., Li H., Wang W. "MQL milling of TC4 alloy by dispersing graphene into vegetable oil-based cutting fluid". Int. J. Advanced Manufacturing Technology. 99 (2018): 1735-1753, https://doi.org/10.1007/ s00170-018-2576-7.

[13] Gűnan F., Kivak T., Yildrim C., Sarikaya M. "Performance evaluation of $\mathrm{MQL}$ with $\mathrm{Al}_{2} \mathrm{O}_{3}$ mixed nanofluids prepared at different concenrations in milling of Hastelloy C276 alloy". J. Materials Research and Technology. 9, 5 (2020): 10386-10400 , https://doi.org/10.1016/j.jmrt.2020.07.018.

[14] Samuel J., Rafiee J., Dhiman P., Yu Z., Koratkar N. "Graphene colloidal suspensions as high performance demi-synthetic metalworking fluids". J. Physical Chemistry. 115 (2011): 3410-3415, https://doi.org/10.1021/jp110885n.

[15] Kadirgama K. "Nanofluid as an alternative coolant in machining: a review". J. Advanced Research in Fluid Mechanics and Thermal Sciences. 69 (2020): 163-173, https://doi. org/10.37934/arfmts.69.1.163173.

[16] Minh D.T., The L.T., Bao N.T. "Performance of $\mathrm{Al}_{2} \mathrm{O}_{3}$ nanofluids in minimum quantity lubrication in hard milling of 60Si2Mn steel using cemented carbide tools". Advances in Mechanical Engineering. 9, 7 (2017): 1-9, https://doi org/10.1177\%2F1687814017710618.

[17] Lee P.H., Nam J.S., Li C., Lee S.W. "An experimental study on micro-grinding process with nanofluid minimum quantity lubrication (MQL)". Int. J. Precision Eng. Manuf. 13 (2012): 331-338, https://doi.org/10.1007/s12541-012-0042-2.

[18] Nam J.S., Lee P.H., Lee S.W. "Experimental characterization of micro-drilling process using nanofluid minimum quantity lubrication". Int. J. Mach. Tools. Manuf. 51 (2011): 649-652, https://doi.org/10.1016/j.ijmachtools.2011.04.005.

[19] Grzesik W. "Media-assisted machining processes using nano-fluids. Part 1: Properties and mechanisms of nano-fluids interaction” („Hybrydowe procesy skrawania wspomagane nanocieczami. Część 1: Właściwości i mechanizmy oddziaływania nanocieczy"). Mechanik. 2 (2021): 6-9, https://doi.org/10.17814/mechanik.2021.2.3 